\title{
L'écriture de la filiation, dir. S. JIȘA, B.-L. BARTOș et Y.
} GOGA

\section{Gabriella Bosco}

\section{CpenEdition \\ Journals}

\author{
Edizione digitale \\ URL: https://journals.openedition.org/studifrancesi/23382 \\ DOI: 10.4000/studifrancesi.23382 \\ ISSN: 2421-5856

\section{Editore} \\ Rosenberg \& Sellier \\ Edizione cartacea \\ Data di pubblicazione: 1 avril 2020 \\ Paginazione: 235 \\ ISSN: 0039-2944 \\ Notizia bibliografica digitale \\ Gabriella Bosco, «L'écriture de la filiation, dir. S. JIȘA, B.-L. BARToȘ et Y. gOGA», Studi Francesi [Online], 190 \\ (LXIV | I) | 2020, online dal 01 mai 2020, consultato il 03 août 2021. URL: http:// \\ journals.openedition.org/studifrancesi/23382 ; DOI: https://doi.org/10.4000/studifrancesi.23382
}

Questo documento è stato generato automaticamente il 3 août 2021.

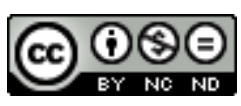

Studi Francesi è distribuita con Licenza Creative Commons Attribuzione - Non commerciale - Non opere derivate 4.0 Internazionale. 


\title{
L'écriture de la filiation, dir. S. JIșA, B.- L. BARTOș et Y. GOGA
}

\author{
Gabriella Bosco
}

\section{NOTIZIA}

L'écriture de la filiation, dir. S. JIșA, B.-L. BARTOș et Y. GOGA, Cluj-Napoca (Roumanie), Casa CărȚii de știin., 2019, «Romanul francez actual», 154 pp.

1 Realizzato sotto l'egida del Centre d'Étude du Roman Français Actuel (CERFA) e del Département de Français de la Faculté des Lettres de l'Université di Cluj-Napoca che hanno organizzato il 19 maggio 2018 una giornata di studi dedicata alla scrittura di filiazione, il volume rende conto del nascere critico di una nozione che, in seguito al trentennio di ricerca di definizioni sempre più conflittuali per le scritture del ventaglio autobiografico, è venuta a designare un genere a volte indicato come "intergenerazionale", o "romanzo di famiglia", più tradizionalmente "saga", "racconto d'infanzia" e simili. Se è vero che il romanzo domina in questo genere di scrittura, scrivono i curatori nella loro breve introduzione (Avant-propos, pp. 5-6), anche la poesia e il teatro possono a loro volta dar luogo a scritture di filiazione. La filiazione presuppone l'esistenza di un figlio o una figlia e di un padre o una madre biologici o spirituali o adottivi, visti nell'ottica della verticalità temporale e delle eredità implicite o esplicite. Comporta anche una ricerca identitaria che si focalizza sulla struttura più $o$ meno esplosa della famiglia la quale, allargata, comprende i nonni, gli antenati, la tribù, così come ogni essere umano che ha avuto un impatto sulla personalità dell'individuo.

2 Si tratta di una forma di scrittura, dicono ancora i curatori del volume, che si presta ad analisi psicologiche, sociologiche, tematiche o genetiche. I contributi presentati, nella loro notevole varietà, attraversano continenti ed epoche per mettere in luce la rete complessa che la filiazione tesse in ambito letterario.

Due le sezioni, che circoscrivono due diverse filiazioni: «De la famille à l'écriture» la prima; «Filiation spirituelle» la seconda. Alina-Liana PINTICAN inaugura la prima sezione 
studiando le Vies minuscules di Pierre Michon (pp. 9-27), testo al cui centro c'è l'interrogazione sulla paternità. Modibo DIARRA indaga tradizione e esoterismo nel racconto di famiglia dell'Enfant noir di Camara Laye (pp. 28-43). Omaïma MACHKOUR dedica il suo contributo al Vestiaire de l'enfance di Patrick Modiano, e all'inscrizione del corpo nella sua scrittura (pp. 44-53). Dora MANASTIRE analizza invece il rancore in Michel Houellebecq, di cui studia il legame filiale individuandolo nel suo delinearsi tra dissoluzione e sparizione (pp. 54-68). E Bianca-Livia BARTOș a sua volta studia, nell'opera di Hervé Bazin, quella che battezza una «défilialisation ratée» (pp. 69-84).

4 La seconda sezione si apre con il contributo di Alexandtra dedicato a Albucius, il "gemello" latino di Pascal Quignard (pp. 87-102). Emanuel TURC analizza la filiazione spirituale che si instaura tra maestro e discepolo nel caso di Bénédicte Heim e di Daniel Pennac, due scrittori francesi nati a distanza di circa 25 anni uno dall'altro (Pennac nel 1944, Heim nel 1970) ed entrambi destinati alla scrittura fin dall'infanzia, una passione nata in contesto scolastico e per intervento attivo di un insegnante che consegna all'allieva o all'allievo il dono della lettura (pp. 103-115). Risalendo il fiume della storia letteraria, Daniela-Ionela covRIG studia invece il rapporto di filiazione rispetto all'opera di Zola, sia in senso attivo (gli autori che ha influenzato) sia passivo (gli autori dai quali è stato influenzato) sia, infine, indagando la nozione di filiazione presente all'interno dei suoi romanzi (pp. 117-127). Mentre torna poi alla letteratura dell'extrême contemporain Roxana MAXIMILEAN che studia la figura dell'antenata nell'opera di Sylvie Germain (pp. 128-142). E conclude il volume l'intervento di Alexandra BOROD che analizza la raccolta intitolata Alliés substantiels di René Char, dal punto di vista della relazione di scambio e interferenza che l'autore vi instaura tra pittura e poesia. 